\title{
Neuroendocrine response to standing and mild exercise in patients with untreated severe congestive heart failure and chronic constrictive pericarditis
}

Roberto Ferrari, Inder S Anand, Claudio Ceconi, Federica De Giuli, Philip A Poole-Wilson, Peter Harris

\begin{abstract}
Objectives-Plasma hormones at rest in patients with untreated severe congestive cardiac failure are similar to those occurring during heavy exercise in healthy people. This study examines the hypothesis that the neuroendocrine effects of exercise are modified in untreated congestive cardiac failure.

Design-The effect of lying, standing, upright exercise, and recovery on several plasma hormones was measured in healthy controls and 2 groups of patients with severe untreated heart failure. The level of exercise was the same in all groups and low enough to be within the capacity of patients with severe failure.

Patients-There were 12 healthy controls, 9 patients with untreated severe congestive cardiac failure caused by myocardial disease, and 12 patients with untreated constrictive pericarditis.
\end{abstract}

Setting-A tertiary referral centre in North India.

Results-Heart rate, noradrenaline, renin activity, aldosterone, cortisol, growth hormone and atrial natriuretic peptide (ANP) were higher in the 2 groups of patients than in the healthy controls during both rest and exercise $(P<0.01$ for both comparisons). In general, the effects of this mild degree of exercise were no greater than those of standing. The increase in heart rate during exercise was greater in the group with constrictive pericarditis than in the controls $(P=$ $0.04)$ and (non-significantly) in congestive heart failure. Apart from these differences the pattern of responses to standing and exercise was similar in the three groups.

Conclusions-While there was evidence of a broad neuroendocrine activation in patients with congestive cardiac failure, the only abnormal increase during exercise (of marginal significance) was found for renin activity in those with myocardial disease. In patients with untreated congestive failure, a substantially normal endocrine response to exercise was superimposed on abnormal resting concentrations.

(Heart 1996;76:50-55)
Keywords: congestive heart failure, neuroendocrine response, constrictive pericarditis, exercise.

The severity of congestive cardiac failure is usually graded according to the symptoms reported by the patients and to the amount of physical activity that is associated with dyspnoea and fatigue. Thus exercise testing has assumed a position of importance in the objective assessment of such patients. In overt untreated congestive cardiac failure or chronic constrictive pericarditis there is an activation of the neuroendocrine system at rest. ${ }^{12}$ The neurohumoral response to exercise in healthy people is in many ways similar to that in congestive cardiac failure ${ }^{3-5}$ and it would not be surprising if the response to exercise were more intense in cardiac patients. This thesis has not, however, been proved; partly because of the rarity with which patients with severe congestive cardiac failure are referred to hospital without previous treatment, and partly because of the difficulty in matching the response to exercise in healthy people with the very limited capacity for exercise of cardiac patients.

Francis et al found that, compared with healthy people, patients with moderate degrees of congestive cardiac failure had an abnormally large increase in plasma noradrenaline during exercise for an equivalent increase in oxygen uptake. ${ }^{6}$ Kirlin $e t a l^{7}$ on the other hand, did not find an abnormally large increase in plasma noradrenaline during equivalent levels of exercise in patients with moderately severe cardiac failure. Exercise normally increases plasma renin activity, ${ }^{4}$ but it is not certain whether this response is increased in congestive cardiac failure. In a study of untreated patients with mild congestive cardiac failure, Bayliss et al found that plasma renin activity increased significantly during exercise but remained within normal limits. ${ }^{8}$ Plasma concentrations of several other hormones are increased during exercise, including vasopressin, aldosterone, and growth hormone, ${ }^{4}$ but we do not know whether this response is modified in congestive heart failure.

We measured plasma adrenaline, noradrenaline, renin activity, aldosterone, vasopressin, cortisol, growth hormone, prolactin, and atrial natriuretic peptide (ANP). We used the same level of gentle exercise to compare responses in healthy controls with those in patients with 
severe congestive cardiac failure that had never been treated.We did not investigate the effect of maximal exercise but instead we studied a level of exercise that was likely to be within the limited range of these very ill patients. ${ }^{9}$ In this way, we compared a group of healthy controls with a group of untreated patients with oedema caused by severe myocardial disease and a group of untreated patients with oedema caused by chronic constrictive pericarditis.

Because the initiation of exercise is often accompanied by a change in posture, we also separately studied the effects of rising from a recumbent to an upright position.

\section{Patients and methods \\ PATIENTS}

The studies were carried out on 12 healthy controls, nine patients with severe untreated congestive cardiac failure, and 12 patients with untreated constrictive pericarditis. Written, informed consent was obtained from the patients and the volunteers. The experimental protocol was approved by the hospital ethics committee. All studies were carried out at the Postgraduate Institute of Medical Education and Research, Chandigarh, India. Hormone concentrations were measured in Brescia, Italy. The haemodynamic, body fluid compartment, and plasma hormone data on some of these patients at rest has been reported elsewhere. ${ }^{12}$

\section{HEALTHY CONTROLS}

The mean (SEM) age of the healthy controls was $32(9.2)$ years. They were all men. None was in a state of athletic training. Extracellular volume was 227 (13) $\mathrm{ml} / \mathrm{kg}$ and total body exchangeable sodium $45(1.9) \mathrm{mmol} / \mathrm{kg}$.

\section{MYOCARDIAL DISEASE}

The cause of congestive cardiac failure was ischaemic heart disease in two patients and idiopathic dilated cardiomyopathy in seven patients. The diagnosis was established by cardiac catheterisation. There were four men and five women, aged $43(5 \cdot 1)$ years. The mean duration of the symptoms was $8(0.5)$ months. All were short of breath (mean New York Heart Association class 3.5 (0.3)). All had oedema of the ankles, raised jugular venous pressure, and enlargement of the liver. Signs of ascites were present in five patients. The mean cardiothoracic ratio was $66(0 \cdot 6)$. The mean right atrial pressure was $13(1.9) \mathrm{mm}$ $\mathrm{Hg}$ and the pulmonary wedge pressure was 28 $(2.3) \mathrm{mm} \mathrm{Hg}$. The cardiac index was $1.7(0.2)$ $1 / \mathrm{min} / \mathrm{m}^{2}$. The left ventricular ejection fraction was $30.5(1 \cdot 1) \%$. Extracellular volume was 296 (28) $\mathrm{ml} / \mathrm{kg}$ and total body exchangeable sodium $60(4 \cdot 2) \mathrm{mmol} / \mathrm{kg}$. None of the patients had ever received any form of treatment for cardiac failure.

\section{CONSTRICTIVE PERICARDITIS}

The probable cause of constrictive pericarditis was tuberculosis, but this was confirmed by bacteriology in only eight patients. The mean age of this group of patients was 29 (3.4) years and the mean duration of the symptoms was $8 \cdot 3(1 \cdot 3)$ months. There were ten males and two females. All were short of breath (mean New York Heart Association class $2.9(0 \cdot 2)$ ). All had oedema of the ankles, increased jugular venous pressure, hepatic enlargement and, with the exception of one patient, ascites. The mean cardiothoracic ratio was $0.50(0.02)$. The mean right atrial pressure was $20(1 \cdot 7)$ $\mathrm{mm} \mathrm{Hg}$ and the pulmonary wedge pressure 23 $(1.4) \mathrm{mm} \mathrm{Hg}$. The cardiac index was $1.9(0.2)$ $1 / \mathrm{min} / \mathrm{m}^{2}$. The mean left ventricular ejection fraction measured by ventriculography was $69.6(0.9) \%$. Extracellular volume was 414 (19) $\mathrm{ml} / \mathrm{kg}$ and total body exchangeable sodium $72(3 \cdot 1) \mathrm{nmol} / \mathrm{kg}$. It is our normal practice to withhold cardiac medication from patients with constrictive pericarditis while they await cardiac surgery. ${ }^{2}$ Therefore, none of the patients included in the present study had received any treatment for their heart disease for at least a month. The diagnosis of constrictive pericarditis was confirmed in all patients at surgery.

\section{PROTOCOLS}

Haemodynamics, fluid compartments, and renal function

These measurements were made on all patients on the second or third day after admission. The techniques have been described previously. ${ }^{12}$

\section{Exercise}

The exercise test was carried out at $1600 \mathrm{~h}$ to avoid diurnal variation. Volunteers and patients had taken a normal breakfast and a light lunch between 1200 and $1300 \mathrm{~h}$. Each of them rested in bed quietly for 30 minutes before the test. An indwelling venous cannula was inserted in one arm and a sphygmomanometer cuff applied to the other.

Blood samples of $5 \mathrm{ml}$ were drawn on five occasions. The first sample was taken after the patient had been supine for 30 minutes. The second sample was taken 6 minutes later, while the patient was still supine. The average of these two samples were taken as the basal lying value. The third sample was drawn after the patient had been standing for 10 minutes. The subject then exercised for 6 minutes on a treadmill with a gradient of $0^{\circ}$. For the first 3 minutes the treadmill was run at $1 \mathrm{mph}$ $(1.6 \mathrm{~km} / \mathrm{h})$. After 3 minutes, the speed of the treadmill was increased to $1.5 \mathrm{mph}$, but the gradient was kept at $0^{\circ}$. The fourth sample was taken at the end of 6 minutes of exercise, while the patient was still standing.

The patient was then asked to lie down and the last sample was obtained after a further 20 minutes. The pulse and blood pressure were monitored after each blood sample was taken.

The volunteers had no difficulty in completing the exercise test. The patients found it difficult but, with encouragement, all of them were able to complete the protocol. The oxygen consumption, measured using this protocol in a normal group and in two groups of patients with different degrees of cardiac failure, was $9 \mathrm{ml} / \mathrm{min} / \mathrm{kg}$ for the first stage of the 
exercise test and $12 \mathrm{ml} / \mathrm{min} / \mathrm{kg}$ for the second stage. ${ }^{9}$ Patients with severe cardiac failure would not be expected to achieve an oxygen consumption of more than $14 \mathrm{ml} / \mathrm{min} / \mathrm{kg}$. The level of exercise undertaken by our patients was, therefore, near their maximum.

\section{Plasma hormones}

We measured renin activity and the concentrations of noradrenaline, adrenaline, aldosterone, vasopressin, cortisol, growth hormone, prolactin, and atrial natriuretic peptide in the plasma by methods described elsewhere. ${ }^{1} 101$ Noradrenaline and adrenaline were measured by high-performance liquid chromatography with electrochemical detection. All the other hormones were measured by radioimmunoassay with standard commercial kits. The radioimmunoassay for atrial natriuretic peptide (ANP) followed extraction with a SepPack C18-column. ${ }^{125}$ I-synthetic alpha-h-ANP (Eiken, Immunochemical, Tokyo, Japan) and rabbit anti-alpha-h-ANP antibody (Eiken)

Effects of standing and exercise in healthy controls and patients with oedema from untreated myocardial disease or constrictive pericarditis

\begin{tabular}{|c|c|c|c|c|c|c|}
\hline & \multicolumn{2}{|l|}{ Controls } & \multicolumn{2}{|c|}{ Myocardial disease } & \multicolumn{2}{|c|}{ Constrictive pericarditis } \\
\hline & Mean (SEM) & $n$ & Mean (SEM) & $n$ & Mean (SEM) & $n$ \\
\hline \multicolumn{7}{|c|}{ Heart rate (beats/min): ${ }^{\star \star \star}$} \\
\hline Rest & $74(1 \cdot 8)$ & 12 & $99(5 \cdot 2)$ & 9 & $99(3 \cdot 1)$ & 12 \\
\hline Standing & $84(2 \cdot 7)$ & 12 & $107(5 \cdot 0)$ & 9 & $102(3 \cdot 7)$ & 12 \\
\hline Exercise & $94(2.9)$ & 12 & $127(4 \cdot 8)$ & 9 & $121(3 \cdot 3)$ & 12 \\
\hline Recovery & $79(2 \cdot 6)$ & 12 & $105(3 \cdot 6)$ & 9 & $99(2 \cdot 8)$ & \\
\hline \multicolumn{7}{|c|}{$\begin{array}{l}\text { Systolic arterial pressure } \\
(\mathrm{mm} \mathrm{Hg})^{\star \star \star}\end{array}$} \\
\hline Rest & $113(2 \cdot 9)$ & 12 & $123(6 \cdot 0)$ & 9 & $107(3.5)$ & 12 \\
\hline Standing & $109(3 \cdot 7)$ & 12 & $118(7 \cdot 0)$ & 9 & $103(3 \cdot 3)$ & 12 \\
\hline Exercise & $125(3 \cdot 8)$ & 12 & $135(7 \cdot 9)$ & 9 & $117(3 \cdot 5)$ & 12 \\
\hline Recovery & $112(3.0)$ & 12 & $124(6 \cdot 4)$ & 9 & $108(3 \cdot 2)$ & 12 \\
\hline \multicolumn{7}{|c|}{ Adrenaline $(\mathrm{pg} / \mathrm{ml})$ : } \\
\hline Rest & $93(20 \cdot 4)$ & 12 & $108(18 \cdot 0)$ & 9 & $81(15 \cdot 5)$ & 11 \\
\hline Standing & $107(20 \cdot 8)$ & 12 & $135(22 \cdot 5)$ & 9 & $101(24 \cdot 3)$ & 11 \\
\hline Exercise & $115(25 \cdot 6)$ & 12 & $95(13 \cdot 5)$ & 9 & $102(20 \cdot 7)$ & 11 \\
\hline Recovery & $99(29 \cdot 5)$ & 12 & $92(16 \cdot 2)$ & 9 & $132(58 \cdot 3)$ & 10 \\
\hline \multicolumn{7}{|c|}{ Noradrenaline $(\mathrm{pg} / \mathrm{ml}):^{\star \star \star}$} \\
\hline Rest & $272(41 \cdot 9)$ & 12 & $824(89)$ & 9 & $940(172)$ & 12 \\
\hline Standing & $403(49 \cdot 8)$ & 12 & $1073(174)$ & 9 & $1164(181)$ & 12 \\
\hline Exercise & $462(44 \cdot 3)$ & 12 & 1125 (126) & 9 & $1245(231)$ & 12 \\
\hline Recovery & $361(47 \cdot 8)$ & 12 & 864 (125) & 9 & $1081(208)$ & 12 \\
\hline \multicolumn{7}{|c|}{ Renin activity $(\mathrm{ng} / \mathrm{ml} / \mathrm{h}):^{\star \star \star}$} \\
\hline Rest & $0.5(0 \cdot 1)$ & 12 & $1.3(0.5)$ & 9 & $4 \cdot 3(1 \cdot 3)$ & 12 \\
\hline Standing & $0.9(0.2)$ & 12 & $1.6(0 \cdot 7)$ & 9 & $4.8(1 \cdot 7)$ & 12 \\
\hline Exercise & $0.8(0 \cdot 1)$ & 12 & $2 \cdot 2(0 \cdot 7)$ & 9 & $6.0(1 \cdot 8)$ & 12 \\
\hline Recovery & $0.7(0 \cdot 1)$ & 12 & $1 \cdot 8(0 \cdot 7)$ & 9 & $5 \cdot 1(1 \cdot 7)$ & 11 \\
\hline \multicolumn{7}{|c|}{ Aldosterone $(\mathrm{pg} / \mathrm{ml}):^{\star}$} \\
\hline Rest & $52(9 \cdot 1)$ & 12 & $112(31 \cdot 6)$ & 9 & $176(47 \cdot 9)$ & 11 \\
\hline Standing & $59(10 \cdot 7)$ & 12 & $144(36 \cdot 1)$ & 9 & $185(55 \cdot 7)$ & 11 \\
\hline Exercise & $86(16.9)$ & 12 & $231(64.5)$ & 9 & $185(59 \cdot 9)$ & 11 \\
\hline Recovery & $79(10 \cdot 4)$ & 12 & $211(68 \cdot 5)$ & 9 & $202(63 \cdot 7)$ & 11 \\
\hline \multicolumn{7}{|c|}{ Vasopressin $(\mathrm{pg} / \mathrm{ml})^{\star}$} \\
\hline Rest & $7 \cdot 3(1 \cdot 3)$ & 12 & $10 \cdot 6(2 \cdot 8)$ & 7 & $8.0(1 \cdot 7)$ & 11 \\
\hline Standing & $9 \cdot 3(3.4)$ & 12 & $15 \cdot 2(6 \cdot 0)$ & 7 & $6.6(0.9)$ & 11 \\
\hline Exercise & $6 \cdot 6(1 \cdot 8)$ & 12 & $10 \cdot 6(2 \cdot 1)$ & 7 & $6.4(0.6)$ & 11 \\
\hline Recovery & $6 \cdot 3(1 \cdot 6)$ & 12 & $9.0(2.4)$ & 7 & $6.6(0.8)$ & 11 \\
\hline \multicolumn{7}{|c|}{ Cortisol (ng/ml): $:^{\star \star \star}$} \\
\hline Rest & $68(8 \cdot 7)$ & 12 & $110(10 \cdot 5)$ & 9 & $95(5 \cdot 4)$ & 12 \\
\hline Standing & $74(10 \cdot 6)$ & 12 & $127(13.5)$ & 9 & $102(7 \cdot 7)$ & 12 \\
\hline Exercise & $85(14 \cdot 1)$ & 12 & $131(11 \cdot 0)$ & 9 & $102(5 \cdot 8)$ & 12 \\
\hline Recovery & $75(12 \cdot 3)$ & 12 & $127(12 \cdot 4)$ & 9 & $91(6.0)$ & 12 \\
\hline \multicolumn{7}{|c|}{ Growth hormone $(\mathrm{ng} / \mathrm{ml}):^{\star \star}$} \\
\hline Rest & $2 \cdot 7(2 \cdot 1)$ & 12 & $8 \cdot 1(3 \cdot 0)$ & 9 & $10 \cdot 5(4 \cdot 1)$ & 11 \\
\hline Standing & $3 \cdot 4(2 \cdot 7)$ & 12 & $13.3(3.5)$ & 9 & $10.6(3.6)$ & 11 \\
\hline Exercise & $3 \cdot 2(1 \cdot 6)$ & 12 & $14.2(5.0)$ & 9 & $12.8(3.8)$ & 11 \\
\hline Recovery & $3 \cdot 4(1 \cdot 3)$ & 12 & $11.3(4.3)$ & 9 & $11.4(3.9)$ & 11 \\
\hline \multicolumn{7}{|c|}{ Prolactin (ng/ml): } \\
\hline Rest & $7 \cdot 4(1 \cdot 1)$ & 12 & $8.0(1.5)$ & 9 & $8 \cdot 2(1.5)$ & 12 \\
\hline Standing & $8 \cdot 4(1 \cdot 1)$ & 12 & $7.9(1.4)$ & 9 & $8 \cdot 1(1 \cdot 6)$ & 12 \\
\hline Exercise & $8 \cdot 6(1 \cdot 2)$ & 12 & $8 \cdot 0(1 \cdot 3)$ & 9 & $7 \cdot 8(1.5)$ & 12 \\
\hline Recovery & $7.4(0.9)$ & 12 & $7 \cdot 7(1 \cdot 3)$ & 9 & $7 \cdot 7(1.4)$ & 12 \\
\hline \multicolumn{7}{|c|}{$\begin{array}{l}\text { Atrial natriuretic peptide } \\
(\mathrm{pg} / \mathrm{ml}):^{\star \star \star}\end{array}$} \\
\hline $\begin{array}{l}\text { (Pg/mI): } \\
\text { Rest }\end{array}$ & & & $247(55)$ & 9 & & \\
\hline Standing & $31(9)$ & 12 & 254 (48) & 9 & $100(20)$ & 12 \\
\hline Exercise & $25(6)$ & 12 & 226 (25) & 9 & $95(16)$ & 12 \\
\hline Recovery & $21(4)$ & 12 & 231 (43) & 9 & 85 (16) & 12 \\
\hline
\end{tabular}

Probability values from variance analysis, comparing a particular measurement between the three

${ }^{\star} \mathrm{P}<0.01 ;{ }^{\star \star} \mathrm{P}<0.001 ;{ }^{\star \star \star} \mathrm{P}<0.0001$. were used, according to a previously described method. ${ }^{12}$

\section{STATISTICAL ANALYSIS}

For each measurement, the analysis was designed to answer the following questions: Is there a difference in the baseline measurement between groups? Has the standing-exercise protocol had a significant overall effect, as measured in all three groups together? Are there specific differences in the effects of the standing-exercise protocol between groups?

In each part of the study, a preliminary analysis of variance was made for each measurement. First, the significance of the differences in the general level of each measurement between study groups was established. Second, the significance of the differences between the four conditions of the standingexercise protocol (lying, standing, exercise, and recovery) was established by combining the results from the three different groups. Third, the significance of any alteration in the response of a measurement to the standingexercise protocol between the groups of patients was explored. The analysis underestimated the significance of the differences in each measurement between the four conditions of the standing exercise protocol, because it was not able to take into account the sequential nature of the changes.

Paired $t$ tests were used subsequently to test the significance of increases in measurements between lying and standing and between standing and exercise. Unpaired $t$ tests were used to test for differences between the groups (controls, myocardial disease, and constrictive pericarditis).

Data are presented as mean ( SEM).

\section{Results}

GENERAL DIFFERENCES BETWEEN GROUPS DURING THE STANDING EXERCISE PROTOCOL (TABLE, FIG)

Preliminary analyses of variance showed significant differences $(P<0.01)$ in the baseline value of each measurement between the three groups except for adrenaline and prolactin. The heart rate and plasma noradrenaline, renin activity, aldosterone, cortisol, growth hormone, and ANP were all increased in the two groups of patients.

Significant overall differences were also found between rest, standing, exercise, and recovery with respect to heart rate, arterial pressure, and noradrenaline $(P<0.01$ for each comparison).

The response to standing and exercise did not differ significantly between the three groups.

EFFECTS OF STANDING (TABLE)

Heart rate-Standing caused the heart rate to increase by 10 beats/min in the healthy people $(P=0.001)$, by 8 beats $/ \mathrm{min}$ in the patients with myocardial disease $(P=0.2)$, and by only 3 beats/min in the patients with constrictive pericarditis $(P=0 \cdot 3)$. There were no significant differences in the increase in heart rate 

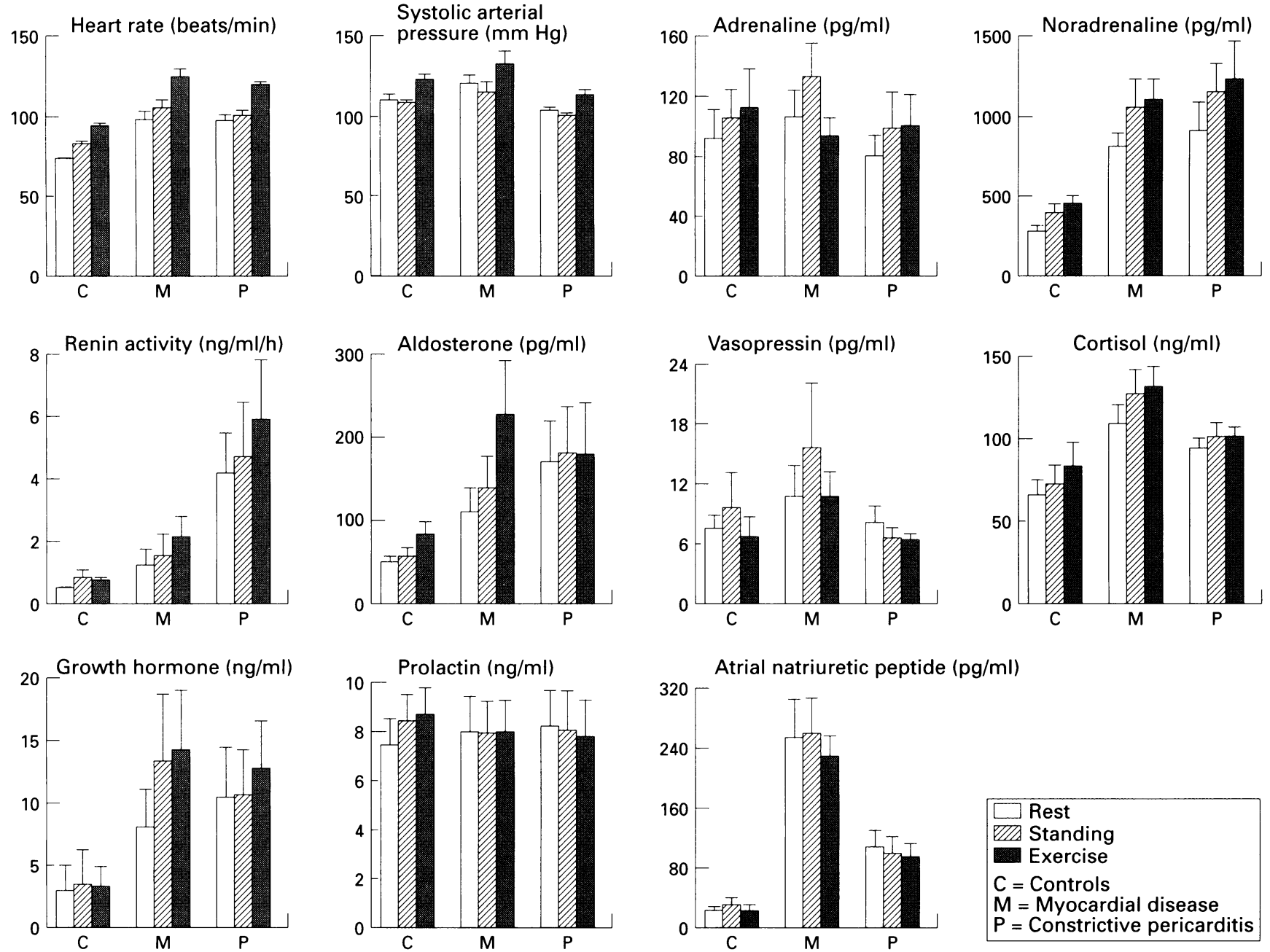

Effects of standing and exercise on heart rate, systolic arterial pressure, adrenaline, noradrenaline, plasma renin activity, noradrenaline, aldosterone, cortisol, growth hormone, prolactin and atrial natriuretic peptide in healthy people and patients with severe, untreated congestive cardiac failure from myocardial disease or constrictive pericarditis.

on standing between the various groups.

Blood pressure-Standing was accompanied by a mean fall in systolic arterial pressure of $3.8 \mathrm{~mm} \mathrm{Hg}$ in the controls, $4.3 \mathrm{~mm} \mathrm{Hg}$ in the patients with myocardial disease, and 3.5 $\mathrm{mm} \mathrm{Hg}$ in the patients with constrictive pericarditis. None of these differences reached statistical significance within a group.

Catecholamines-In all groups the concentrations of noradrenaline and adrenaline in the plasma increased after standing. The increase in noradrenaline was $131 \mathrm{pg} / \mathrm{ml}$ in controls $(P$ $=0.002), 249 \mathrm{pg} / \mathrm{ml}$ in those with myocardial disease $(P=0.2)$, and $224 \mathrm{pg} / \mathrm{ml}$ in those with constrictive pericarditis $(P=0.003)$. The increase in adrenaline was $14 \mathrm{pg} / \mathrm{ml}$ in controls $(P=0.002), 27 \mathrm{pg} / \mathrm{ml}$ in myocardial disease $(P=0.07)$, and $20 \mathrm{pg} / \mathrm{ml}$ in constrictive pericarditis $(P=0 \cdot 2)$. There was no significant difference in either noradrenaline or adrenaline response between the cardiac patients and the controls.

Renin and aldosterone-A non-significant increase in plasma renin activity and aldosterone was seen in each group on standing. There were no significant differences between the groups.

Other hormones-Standing produced no significant changes in the other hormones.
EFFECTS OF EXERCISE (TABLE)

In general, the effects of this mild degree of exercise were no greater than the effects of rising from the lying to the standing position (figure).

Heart rate-Proceeding from standing to exercise caused a further increase in heart rate of 11 beats $/ \mathrm{min}$ in the controls $(P=0.0003)$, 20 beats/min in the patients with myocardial disease $(P=0.003)$, and 19 beats $/ \mathrm{min}$ in the patients with constrictive pericarditis $(\mathrm{P}<0.0001)$. The increase was significantly greater than normal in constrictive pericarditis $(P=0.009)$ but did not differ significantly from normal in myocardial disease $(\mathbf{P}=$ $0.07)$.

Blood pressure-All groups showed an increase in systolic arterial pressure during exercise: $16.3 \mathrm{~mm} \mathrm{Hg}$ in the controls $(P=$ $0.0001), 16.3 \mathrm{~mm} \mathrm{Hg}$ in myocardial disease $(P=0.002)$, and $13.6 \mathrm{~mm} \mathrm{Hg}$ in constrictive pericarditis $(P<0.0001)$. There were no significant differences between the groups.

Catecholamines-Plasma noradrenaline rose during exercise in all three groups, although significantly so only in the controls. The increases were $59 \mathrm{pg} / \mathrm{ml}$ in controls $(P=$ $0.01), 52 \mathrm{pg} / \mathrm{ml}$ in myocardial disease $(\mathbf{P}=$ $0 \cdot 6$ ), and $81 \mathrm{pg} / \mathrm{ml}$ in constrictive pericarditis 
$(P=0 \cdot 2)$. Plasma adrenaline did not change significantly during exercise.

Renin activity and aldosterone-Plasma renin activity did not change during exercise in the controls. It rose in the group with myocardial disease (increase of $0.5 \mathrm{pg} / \mathrm{ml} / \mathrm{h} ; P=0.02$ ) and in the group with constrictive pericarditis (increase of $1.2 \mathrm{pg} / \mathrm{ml} / \mathrm{h} ; P=0.2$ ). The increase was significantly greater in the patients with myocardial disease than in the controls $(P=0.04)$.

A non-significant increase in plasma aldosterone occurred on exercise in the controls and the patients with myocardial disease. There was no change in those with constrictive pericarditis. The difference between the two groups of patients was significant $(P=0.03)$.

Other hormones-Exercise had no significant effect on any of the other hormones.

\section{Discussion}

In this study we useed the same methods to compare patients with severe untreated cardiac failure with healthy people. Patients with untreated heart disease were chosen because it was not clear from earlier reports whether treatment might itself modify the neuroendocrine response to exercise. The exercise protocol and load were identical in the healthy people and the patients, so that a direct comparison could be made. For such comparability, a mild degree of exercise had to be chosen. Thus the level of exercise was low relative to the maximum in the healthy people; but it was near maximum in the patients. This means that the exercise was more stressful in the patients, which might have made the neuroendocrine response more severe. There is little published information on whether the neuroendocrine response in untreated congestive cardiac failure is different from normal.

All patients had severe congestive cardiac failure. The cardiac index was reduced, the heart rate was rapid, and pressures in the pulmonary circulation and in the right atrium were increased. The right atrial pressure was particularly high in patients with chronic constrictive pericarditis. The systemic arterial pressure was normal in both groups of patients, which is consistent with the hypothesis that the neuroendocrine response leading to the oedematous syndrome contributes to the maintenance of blood pressure. ${ }^{1314}$ Retention of water and sodium was confirmed by appropriate measurements.

Analysis of variance showed that considerable differences in the heart rate, arterial pressure, and levels of plasma hormones separated the two groups of patients from the healthy controls. The analysis of variance does not take into account the sequential nature of the conditions of lying, standing, exercise, and recovery; but it is clear that the differences we report were mainly determined by the initial, basal values while the patients were lying down.

The standing-exercise protocol had the same significant overall effects in all three groups of subjects-with no significant differences between the three groups in the effects of the protocol on any factor studied. Thus, from the analysis of variance alone, no specific effect of congestive failure on the response to exercise could be detected.

Separate analyses by $t$ tests of the increases during standing did not reveal any specific difference in the response between the cardiac patients and the healthy people. Levine et al reported a normal response of plasma renin activity and noradrenaline to tilt in patients with congestive cardiac failure who had normal resting haemodynamics, but a diminished response in those patients who had abnormal resting haemodynamics. ${ }^{15}$ The haemodynamic response to tilt was similar in their two groups of patients. In our patients, the response of plasma noradrenaline to standing was, if anything, greater in the cardiac patients. The act of standing is, however, not entirely comparable with passive tilting.

The increase in heart rate during exercise tended to be greater than normal in the two groups of patients, significantly so in those with constrictive pericarditis ( $t$ test). The arterial pressure rose by about the same amount in all three groups. Francis commented that patients with congestive cardiac failure have an increased heart rate response and a normal arterial pressure response for a given uptake of oxygen. ${ }^{16}$ It is only when the increases are expressed as a function of the maximal oxygen uptake that the responses of the heart rate and arterial pressure in congestive cardiac failure seem to be less than normal. Plasma renin activity rose more during exercise in the two groups of patients, and the increase was significantly greater than normal by $t$ test in myocardial disease.

\section{GENERAL CONCLUSIONS}

The neurohumoral response in congestive cardiac failure seems to be directed to the preservation of arterial pressure. ${ }^{1213141718}$ The neurohumoral response to standing and exercise is similar to that in congestive cardiac failure $^{5}$ and is probably also directed to the maintenance of the arterial pressure and, thereby, perfusion of the tissues.

We found that during exercise the cardiac patients had a greater increase than normal in heart rate (significant only for constrictive pericarditis) and in plasma renin activity (significant only for myocardial disease). We found no other significant difference in the response to the standing-exercise protocol.

Because any differences were small we conclude that, except for the responses of heart rate and perhaps of plasma renin activity during exercise, the neuroendocrine response to standing and exercise is not substantially modified by congestive cardiac failure. Essentially, normal responses are superimposed on an abnormal resting state. This conclusion is, of course, valid only for the limited degree of exercise that can be undertaken by such patients who are extremely ill. This work was supported by the Indian Council of Medical
Research, Italian Research Council (CNR) target Project "Prevention and Control Disease Factor" (87.01485.04 and "Prevention and Control Disease Factor" (87.014 
1 Anand IS, Ferrari R, Kalra GS, Wahi PL, Poole-Wilson P, et al. Edema of cardiac origin. Studies of body water and plasma hormones in untreated congestive cardiac failure. Circulation 1989;80:299-305.

2 Anand IS, Ferrari R, Kalra GS, Wahi PL, Poole-Wilson P Harris P. Pathogenesis of edema in constrictive pericarditis studies of body water and sodium, renal function, hemodynamics and plasma hormones before and after hemodynamics and plasma hormones befo

3 Francis G, Goldsmith S, Levine T, Olivari M, Cohn J. The neurohumoral axis in congestive heart failure. Ann Intern Med 1984:101:370 7

4 Ferrari R, Ceconi C, Rodella A, De Guili F, Panzali A, Harris $P$. Temporal relations of the endocrine response to exercise. Cardioscience 1991;2:131-40.

5 Harris P. Evolution and the cardiac patient. Cardiovasc Res 1983;17:313-9.

6 Francis G, Goldsmith S, Ziesche S, Cohn J. Response of plasma noradrenaline and epinephrine to dynamic exercise in patients with congestive heart failure. $A m \mathcal{F}$ Cardiol 1982;49:1152-6.

7 Kirlin P, Grekin R, Das S, Ballor E, Johnson T, Pitt B. Neurohumoral activation during exercise in congestive heart failure. $A m \mathcal{F}$ Med 1986;81:623-9.

8 Bayliss J, Norell M, Canepa-Anson R, Sutton G, PooleWilson P. Untreated heart failure: clinical and neuroendocrine effects of introducing diuretics. Br Heart $\mathcal{f} 1987$; 57:17-22.

9 Lipkin D, Perrins J, Poole-Wilson P. Respiratory gas exchange in the assessment of patients with impaired exchange in the assessment of patients with im
ventricular function. Br Heart $\mathcal{f}$ 1984;54:321-328.
10 Ferrari R, Ceconi C, Signorini C, Anand I, Harris P, Albertini A. Sample treatment for long-distance transport of plasma for hormone assay. Clin Chem 1989;35 331-2.

11 Ferrari R, Ceconi C, Rodella A, Harris P, Visioli O. Hormonal response in untreated myocardial infarction. Hormonal response in untrea
Cardioscience 1990;1:55-60.

12 Poiesi C, Rodella A, Mantero G, Cannela G, Ferrari R, Albertini A. Improved radioimmunoassay of atrial peptide in plasma. Clin Chem 1989;35:1431-4.

13 Harris $P$. Congestive cardiac failure: central role of the arterial blood pressure. Br Heart $\mathcal{f} 1987 ; 58: 190-203$

14 Harris P. Role of arterial pressure in the oedema of heart disease. Lancet 1988;i:1036-8.

15 Levine T, Francis G, Goldsmith S, Cohn J. The neurohumoral and hemodynamic response to orthostasis tilt in patients with congestive heart failure. Circulation 1983; 67:1070-5.

16 Francis G. Hemodynamic and neurohumoral responses to dynamic exercise: normal subjects versus patients with heart disease. Circulation 1987;76suppl VI:11-6.

17 Anand IS, Chandrashekhar Y, Ferrari R, Sarma R, Guleria $\mathrm{R}$, Jindal $\mathrm{S}$, et al. Pathogenesis of congestive state in chronic obstructive pulmonary disease. Studies of body water and sodium, renal function, hemodynamics, and plasma hormones during edema and after recovery. Circulation 1992;86:12-21.

18 Anand IS, Chandrashekhar Y, Ferrari R, Poole-Wilson PA, Harris PC. Pathogenesis of edema in chronic severe anehemodynamics variables, and plasma hormones. Br Heart f 1993;70:357-62. 